\title{
A new method of objective examination in proctology
}

\author{
RAYMOND P. J. KERREMANS \\ From the Heelkundige Gastro-enterologie, Akademisch Ziekenhuis St. Rafaël, \\ Leuven, België
}

The preparation and use of moulds and casts from cavities and organs has already been applied in several medical disciplines. It is a current method in stomatology in order to obtain an exact reproduction of the oral cavity for preparing dental prostheses. Plastic casts obtained from the filling of vessels, ducts, and cavities are of great interest for the anatomical knowledge of organs (Van der Schueren, 1959). A clinical application of a similar method, using silicone foam, has been published for the diagnosis of lesions of the sigmoid colon (Cook and Margulis, 1962; 1963). An analogous method for examining the anal canal and its function has been elaborated here.

\section{COMPOSITION AND PROPERTIES OF THE USED PRODUCT}

Many plastifying products for making casts of the anal canal have been tested. A mixture of stearic acid, resin, and talc ${ }^{1}$ has given the most satisfactory results for the following reasons. (1) The high grade of plasticity of the product and therefore precise reproduction of the anatomical forms and details of the surface of the anal canal; (2) less degree of shrinkage of the product over the used temperature range from $48^{\circ} \mathrm{C}$ down to $37^{\circ} \mathrm{C}$ being $0.3 \%$, and consequently less distortion of the cast; (3) the material has to be as hard as possible because the cast broadens at the end which is the reproduction of the ampulla recti. The retraction of the hardened cast may be somewhat difficult. Soft material nearly always breaks off at the smallest part of the anal canal which is situated just beyond the broadening of the ampulla recti. The strength of the product also allows easier preservation of the casts; (4) the product also glues very well on other uneven surfaces. During the procedure it adheres firmly to the surface of the injection syringe. This enables easy withdrawal of the whole piece.

\section{TECHNIQUE OF ADMINISTRATION}

Of the product, $50 \mathrm{mg}$ is inserted in a plastic syringe (8 $\mathrm{mm}$ internal diameter and $53 \mathrm{~mm}$ length), from which the narrow needle part has been cut off. The filled syringe is kept in warm water at $48^{\circ} \mathrm{C}$ for three minutes. The warmed and filled syringe is introduced into the anus and pushed up to the lower rectum. At that moment it ${ }^{1}$ Kerr soft green no. 2 impression compound sticks. must be drawn back, and the semi-liquid product injected at the same time. The whole procedure must be effected in a few seconds before the resins start to harden. The nearly empty syringe is left in contact with the injected product outside the anus, in an exact vertical position to fix the orientation of the anal mould. After three minutes, the resins harden reasonably well at the rectal temperature, when the cast can be drawn back by pulling the syringe, without fear of deformity or breaking off. The whole procedure is repeated twice in the same subject, once with maximal contraction of the anal sphincters on the patient in the erect position and second time when the patient squats trying to defaecate. Casts of a resting anal canal cannot be made, as the material is a stimulating factor for the anal mechanisms. Even when asking the patient to be as relaxed as possible, the cast could give a false image of the resting position of the anal canal.

\section{RESULTS}

With the aid of this new technique, the structural relations of the rectum, anal canal, and pelvic outlet have been studied during the state of faecal continence and during defaecation. $A$ priori it has been postulated that the relationship of the above mentioned structures must be at the basis of the physiological mechanism of faecal continence. It is also suggested that well defined changes must arise at the moment of defaecation. Taking into account the constant vertical position of the syringe after the injection of the product and the forward inclination of the pelvic outlet, some measurable differences can be observed between the cast of the contracted anal canal and the one taken during defaecation. The following parameters were measured: length, sagittal diameter, and frontal diameter of the anal canal, the ventral inclination of the anal canal, and the dorsal inclination of the lower part of the rectum (Fig. 1). These parameters represent the objective reflection of the two physiological states of the outlet of the digestive tract. Deviations from these parameters may be an expression of an abnormal function. The quantitative and physiological interpretation of these findings is still under study.

Very soon the value of this moulding technique 

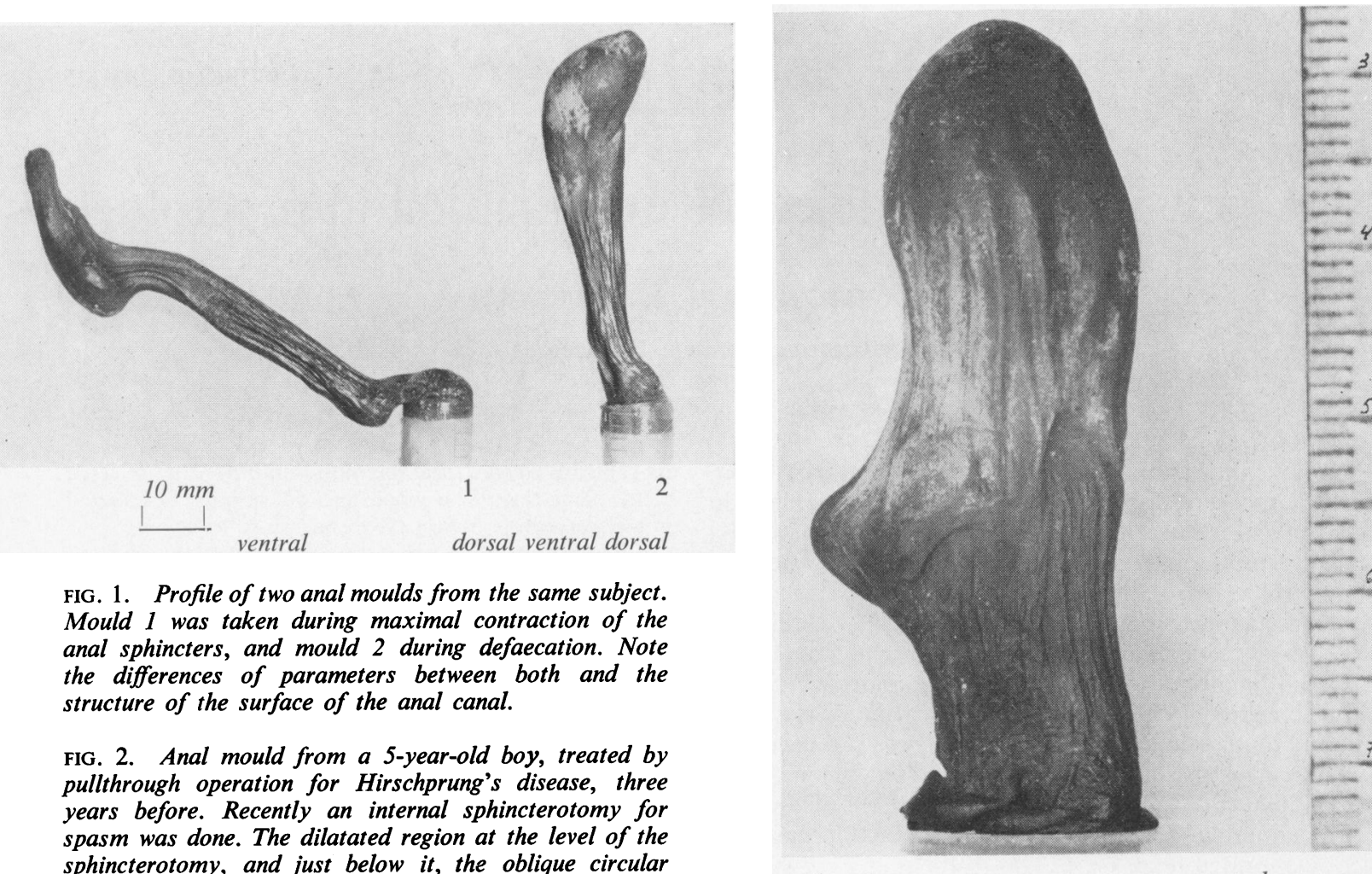

FIG. 1. Profile of two anal moulds from the same subject. Mould 1 was taken during maximal contraction of the anal sphincters, and mould 2 during defaecation. Note the differences of parameters between both and the structure of the surface of the anal canal.

FIG. 2. Anal mould from a 5-year-old boy, treated by pullthrough operation for Hirschprung's disease, three years before. Recently an internal sphincterotomy for spasm was done. The dilatated region at the level of the sphincterotomy, and just below it, the oblique circular suture of the first operation, are visible on the mould.

\section{dorsal}

ventral

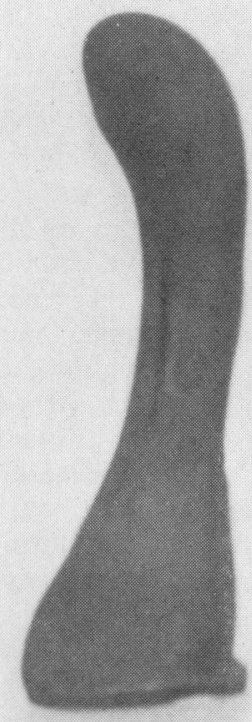

(1)

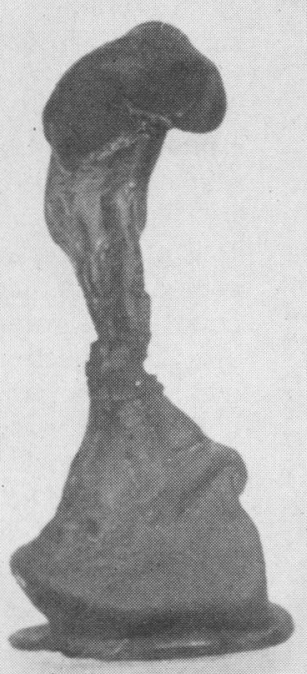

(2)

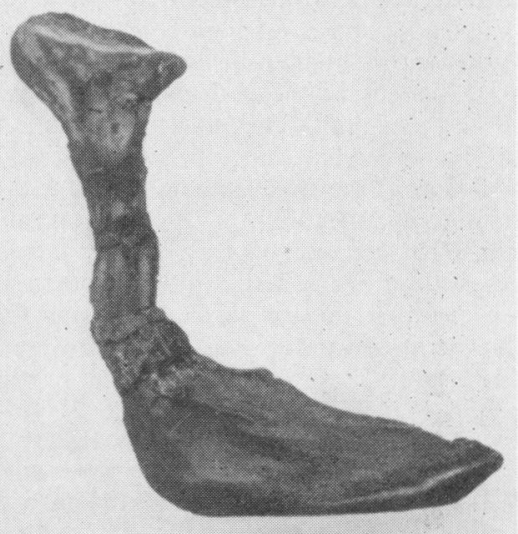

(3)

FIG. 3. Successive moulds from a baby, representing a rare congenital malformation of the anal canal. There was an amount of fibrotic tissue existing in the middle half of the anal canal. Proximal and distal to the circular lesion, the anal epithelium was found to be normal by biopsy. Mould 3 was taken before treatment: the surface is rough, the diameter is narrow and the upper surface is flattened by faecalomas in the rectum. Mould 2 was taken after several dilatations of the canal. Mould 1 represents the state one year later: the surface is covered with normal epithelium, the fibrosis has disappeared, and the diameter has become normal. 
became apparent for the exact demonstration of deformities and lesions of the anal canal. It is a fact that the negative mould gives a much more accurate image of the real dimension and extension of lesions of the anal canal than endoscopic or digital examinations. These examinations are however, made in artificial circumstances, due to the wide dilatation of the anal canal. In this manner the mould technique can be of importance in the study of internal haemorroids, operative sutures, congenital anomalies etc. (Fig. 2). A mould can also be stored and can be studied and compared with others at any time afterwards. This is very useful for the appreciation of the evolution of a lesion or the effect of a treatment. Indeed, the interpretation of successive digital or anoscopic examinations is difficult and may be impossible when done by different examiners. The successive parameters of the casts may be an objective expression of the follow-up of surgical scars in the anal canal, or anal dilatations, or internal sphincterotomies (Fig. 3).
Therefore it is necessary to keep all the conditions when making the casts as constant as possible.

\section{SUMMARY}

A new moulding technique is presented which gives faithful reproductions of the anal canal and lower rectum. If the conditions of the procedure are kept identical, casts taken in different physiological states can be compared. The technique may also be of use in investigating the mechanism of anal continence and defaecation, and for accurately demonstrating and following up lesions in the anal canal.

\section{REFERENCES}

Cook, G. B., and Margulis, A. R. (1962). The use of silicone foam for examining human sigmoid colon. Amer. J. Roentgenol., 87, 633-643.

- (1963). Detecting small sessile colon cancers with silicone foam. J. Amer. med. Ass., 183, 66-68.

Van der Schueren, G. (1959). Cava Vitalia. Arscia Uitgaven N.V., 